01,07

\title{
Анализ усталостного разрушения рельсовой стали
}

\author{
(C) С.А. Атрошенко ${ }^{1}$, С.С. Майер ${ }^{2}$, В.И. Смирнов ${ }^{2}$ \\ ${ }^{1}$ Институт проблем машиноведения РАН, \\ Санкт-Петербург, Россия \\ ${ }^{2}$ Петербургский государственный университет Императора Александра I, \\ Санкт-Петербург, Россия \\ E-mail: satroshe@mail.ru
}

Поступила в Редакцию 21 апреля 2020 г.

В окончательной редакции 21 апреля 2020 г.

Принята к публикации 29 мая 2020 г.

\begin{abstract}
Проведено исследование взаимосвязи между механическими свойствами материала в микрообъемах и свойствами материала, находящегося под нагрузкой. Приведен фрактографический анализ поверхности усталостного излома железнодорожного рельса с внутренней поперечной трещиной. Обсуждается связь фрактографических особенностей со структурой материала. Образец с внутренней поперечной трещиной в головке рельса изъят из эксплуатации после интенсивной циклической нагрузки в стрелочном переводе. Для металлографического исследования образец был подвергнут изгибу по трехточечной схеме. На поверхности излома рельса выявлено три области, различающиеся по характеру разрушения материала.
\end{abstract}

Ключевые слова: рельс, поперечная трещина, излом, усталостное разрушение.

DOI: 10.21883/FTT.2020.10.49898.094

\section{1. Введение}

В связи с увеличением объема грузоперевозок и пассажиров и интенсивностью движения возрастает опасность выхода рельсов из строя, поэтому анализ разрушения деформационных изменений структуры рельсов после длительной эксплуатации является актуальным. Термомеханическое повреждение [1] возникает при скольжении колес по рельсу, когда рельс подвергается многочисленным циклическим нагрузкам, а при увеличении количества циклов увеличивается величина микронапряжений [2]. В результате происходит нагрев поверхности рельса до высокой температуры и охлаждение, что приводит к изменению микроструктуры и появлению микротрещин, которые являются причиной зарождения поперечных усталостных трещин. Началом образования дефекта является возникновение внутренней продольной трещины от поверхности рельса. Развитие продольной трещины приводит к образованию поперечной трещины [3-5]. При малых размерах и большой глубине залегания такие трещины не обнаруживаются дефектоскопами. При планировании работы дефектоскопных средств важно знать, как быстро развивается поперечная трещина под нагрузкой, а также как она распространяется в зависимости от площади поверхности. Для установления причины излома рельса был вырезан образец длиной $1.2 \mathrm{~m}$ с трещиной посередине. Далее образец был подвергнут изгибу по трехточечной схеме головкой вниз до его разделения на части. На поверхности излома проводилось фрактографическое исследование. После этого был вырезан шлиф толщиной примерно $1.5 \mathrm{~cm}$ для металлографического исследования структуры поперечного сечения образца.

\section{2. Материал и методика исследования}

Проведено исследование разрушенного стального рельса, работавшего при переключении стрелки. В качестве материала исследования использовали образцы рельсовой стали Р65, свойства и элементный состав которой регламентируются ГОСТ Р 51685-2013. Доля вязкой составляющей в изломе стали определялась по ASTME 436-03. Исследование поверхности разрушения проводилось на микроскопе Axio Observer Z1-M в темном поле при увеличении $100^{x}$, а микроструктура поперечного сечения анализировалась в светлом поле на том же микроскопе и сканирующем микроскопе марки Phenom. Микротвердость замерялась на приборе SHIMADZU марки HMV-G. Микроанализ отдельных областей проводился с помощью сканирующего микроскопа марки Phenom.

\section{3. Результаты и обсуждение}

Общий вид поверхности разрушения представлен на рис. 1. Как видно из рис. 1, на поверхности разрушения выделяются три зоны. Фрактуры трех зон представлены на рис. 2, а доля вязкой составляющей в изломе этих трех зон разрушения представлена в табл. 1 .

Как видно из представленных данных, наиболее хрупкое разрушение наблюдается в первой зоне - это последний этап разрушения рельса, начинается оно в третьей зоне, распространяется во вторую и заканчивается в первой, где кроме приложенных нагрузок наблюдается и воздействие температуры [6]. В табл. 2 представлена микротвердость зон разрушения. Наибольшая твердость оказалась в средней самой протяженной 


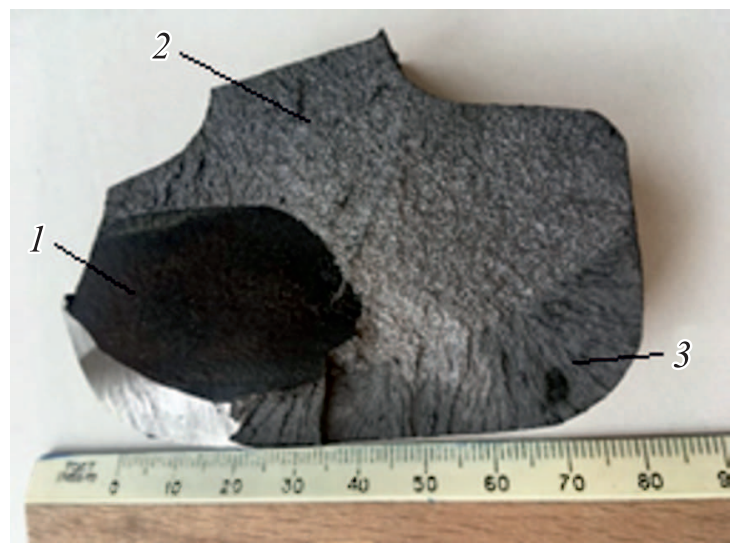

Рис. 1. Вид поверхности разрушения рельса после работы в стрелочном переводе.

зоне разрушения, а самая низкая - в заключительной, где уже произошло разделение образца на части.

\section{Анализ микроструктуры поперечных шлифов стали в трех зонах разрушения}

Область 1. Конечный этап разрушения. В этой области у поверхности разрушения структура
Таблица 1. Доля вязкой составляющей в изломе рельсовой стали

\begin{tabular}{c|c}
\hline $\begin{array}{c}\text { Область } \\
\text { разрушения }\end{array}$ & $\begin{array}{c}\text { Доля волокна } \\
\text { в изломе, \% }\end{array}$ \\
\hline 1 & 96.8 \\
2 & 97.4 \\
3 & 99.4
\end{tabular}

Таблица 2. Микротвердость рельсовой стали в трех зонах разрушения

\begin{tabular}{c|c|c|c}
\hline Зона & $\mathrm{HV}_{\text {average, }}, \mathrm{MPa}$ & Разброс $\mathrm{HV}$ & Отклонение, \% \\
\hline 1 & 315.1 & $300-340$ & 5.7 \\
2 & 333.3 & $319-340$ & 2.5 \\
3 & 315.5 & $311-322$ & 1.3
\end{tabular}

имеет характер течения, где все структурные составляющие смешались (рис. 3,a), а также присутствует разветвленная сетка микротрещин (рис. $3, b, c)$.

В центре этой области (рис. $4, a, b$ ) наблюдается типичная для этой стали структура пластинчатого перлита, а также области динамической рекристаллизации (рис. $4, b, c, d$ ), часто наблюдающиеся при динамическом

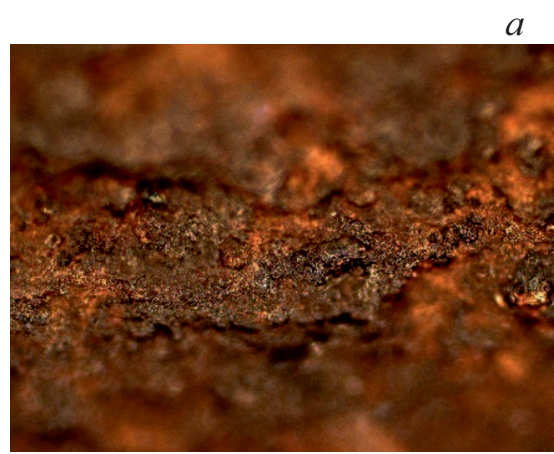

$-100 \mu \mathrm{m}$

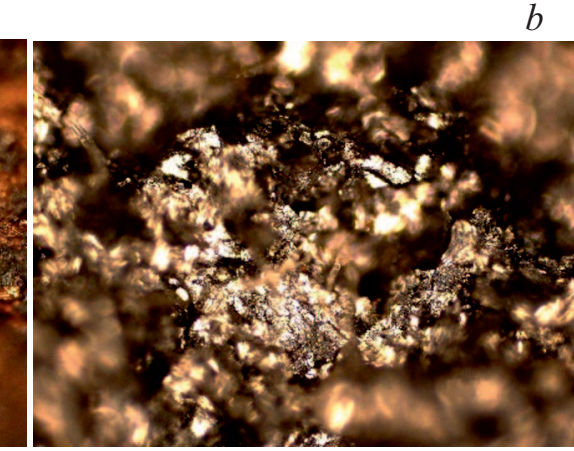

$-100 \mu \mathrm{m}$

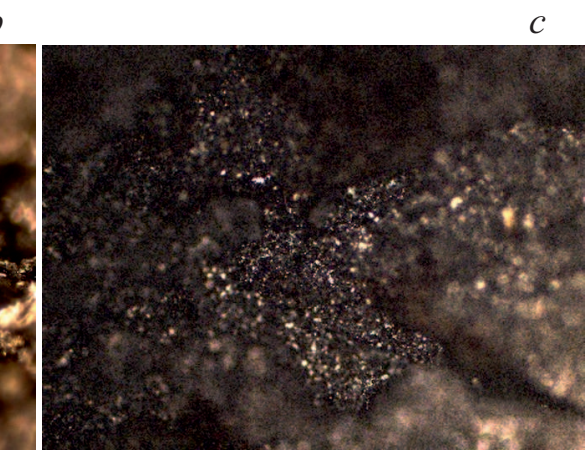

$-100 \mu \mathrm{m}$

Рис. 2. Фрактура зон разрушения: $a-1, b-2, c-3$.

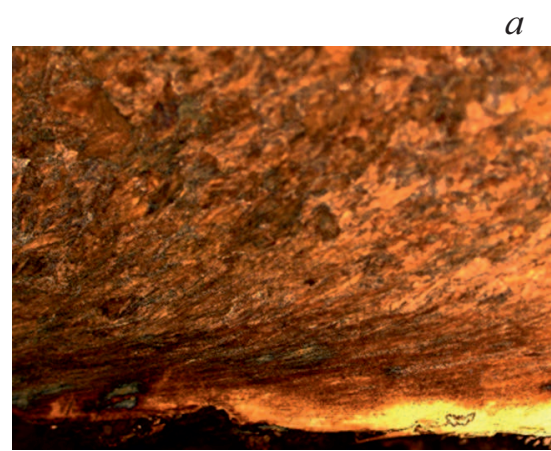

$-20 \mu \mathrm{m}$

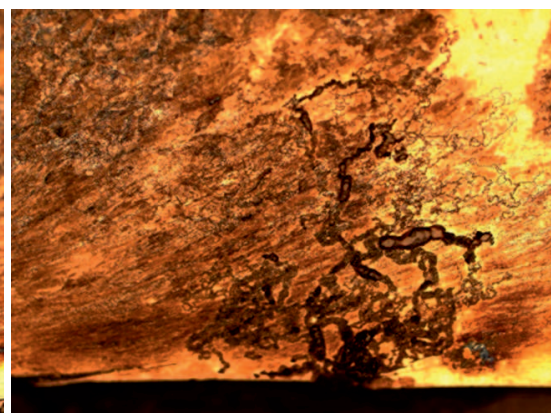

$-20 \mu \mathrm{m}$ $b$

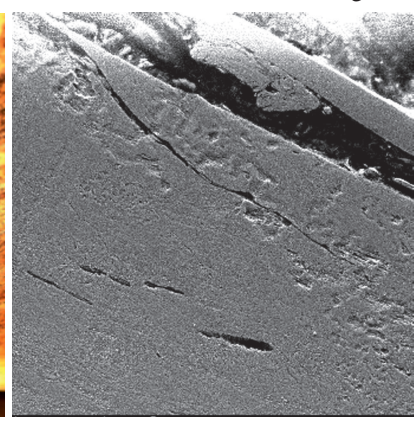

$20 \mu \mathrm{m}$

Рис. 3. Микроструктура у поверхности разрушения области 1. 


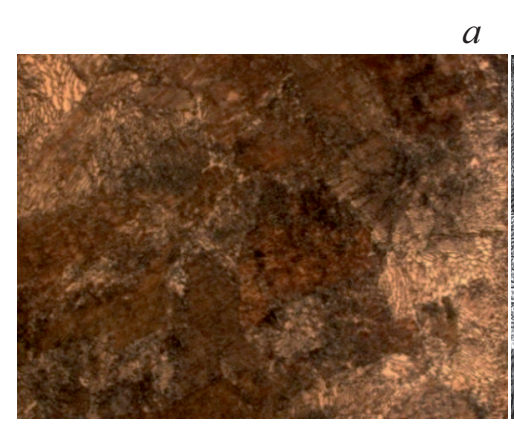

$-5 \mu \mathrm{m}$

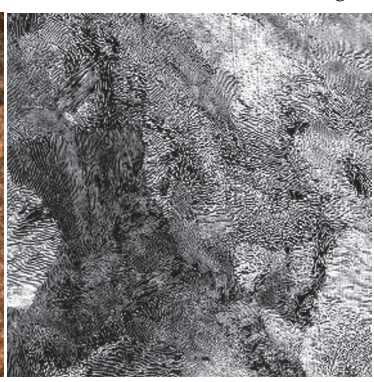

$20 \mu \mathrm{m}$ $b$

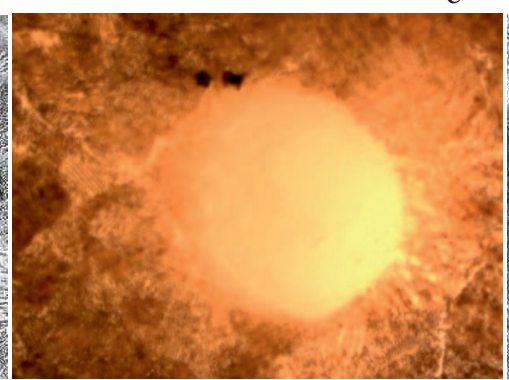

$-10 \mu \mathrm{m}$

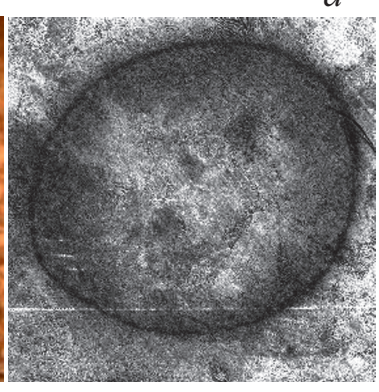

$20 \mu \mathrm{m}$

Рис. 4. Микроструктура в центре области 1.

a

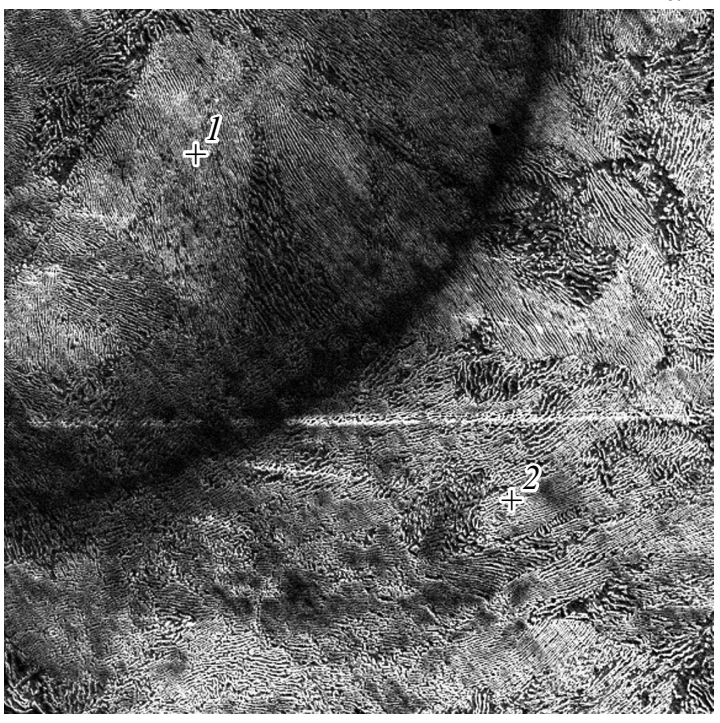

$20 \mu \mathrm{m}$ b

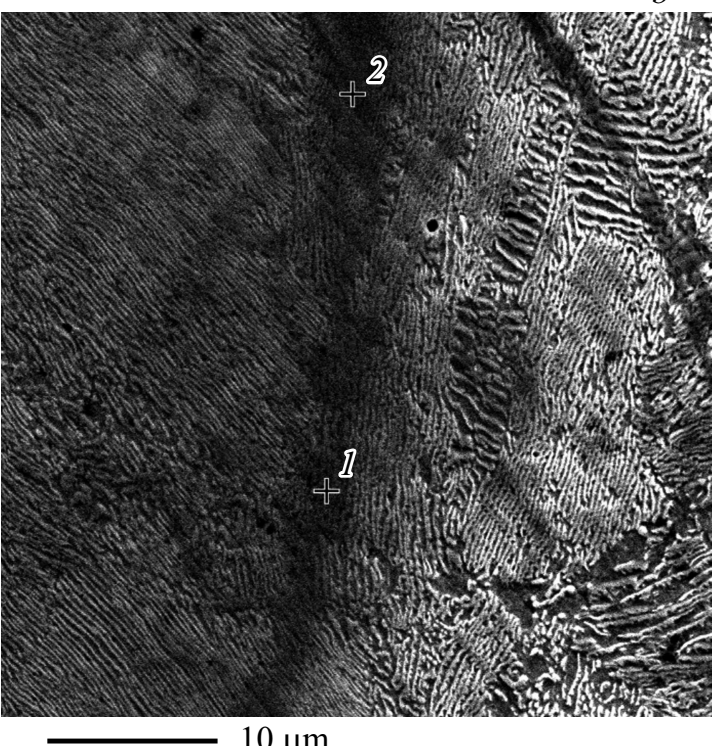

Рис. 5. Зона рекристаллизации.

нагружении [7]. В результате нагрева и быстрого охлаждения в этих областях динамической рекристаллизации наблюдается микрокристаллическая структура вплоть до наноструктуры. В некоторых участках этих областей зерно уже выросло до $4 \mu \mathrm{m}$.

В результате сильного нагрева в некоторых областях произошел отжиг, и пластинчатый цементит превратился в глобулярный, а иногда он растворяется аналогично данным работы [8]. Если в третьей области, с которой начиналось зарождение трещины и разрушение, размер зерна и структурных составляющих - цементита и феррита был мельче (табл. 3), то во второй области эти значения увеличились, а в первой - они максимальные.

Микроанализ области динамической рекристаллизации, проведенный с помощью сканирующего Phenomмикроскопа с возможностью микроанализа, показал почти идентичный химический состав как внутри этого региона (точка +1$)$, так и за ее пределами (точка +2$)$. На рис. 5 показаны области, где был проведен анализ,
Таблица 3. Количественные характеристики микроструктуры рельсовой стали в трех областях разрушения

\begin{tabular}{c|c|c|c}
\hline Зона & $\begin{array}{c}\text { Размер } \\
\text { зерна, } \mu \mathrm{m}\end{array}$ & $\begin{array}{c}\text { Толщина пластин } \\
\text { феррита, } \mu \mathrm{m}\end{array}$ & $\begin{array}{c}\text { Толщина пластин } \\
\text { цементита, } \mu \mathrm{m}\end{array}$ \\
\hline 1 & 28.89 & 1.24 & 0.18 \\
2 & 22.57 & 0.87 & 0.11 \\
3 & 5.75 & 0.72 & 0.07
\end{tabular}

а рис. 6 показывает спектр элементов отмеченных областей. Как видно из рис. 5, $a$, структура внутри области $($ точка +1$)$ (размер ламелей феррита и цементита) намного мельче, чем за ее пределами (точка +2$)$. На рис. $5, b$ отмечены точки на границе области динамической рекристаллизации (точка +1$)$ и (точка +2$)$, их элементный состав тоже практически идентичен между собой и между точками внутри и за пределами динамической рекристаллизации. 


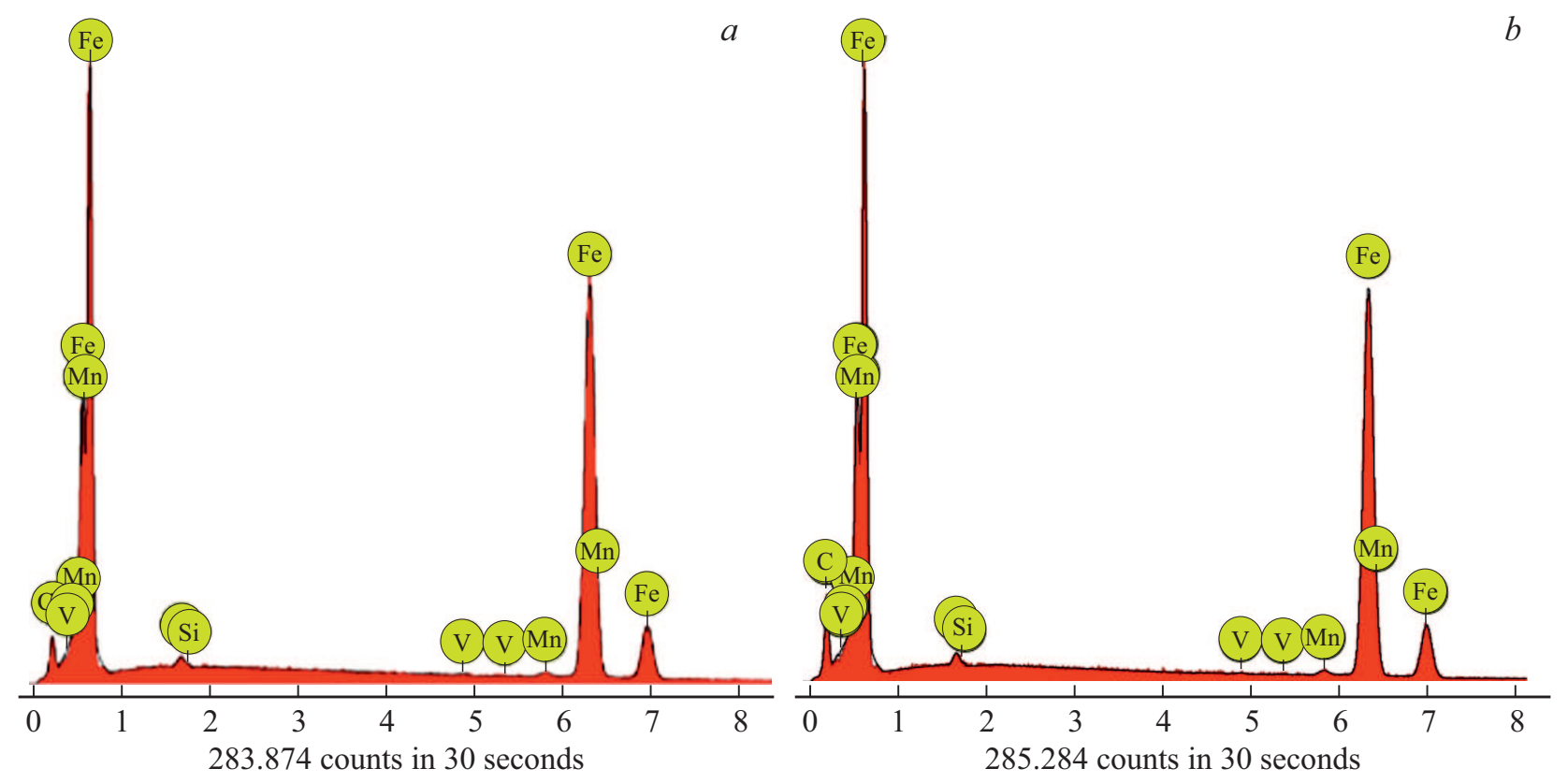

Рис. 6. Спектр элементов в зоне и на границе рекристаллизации.

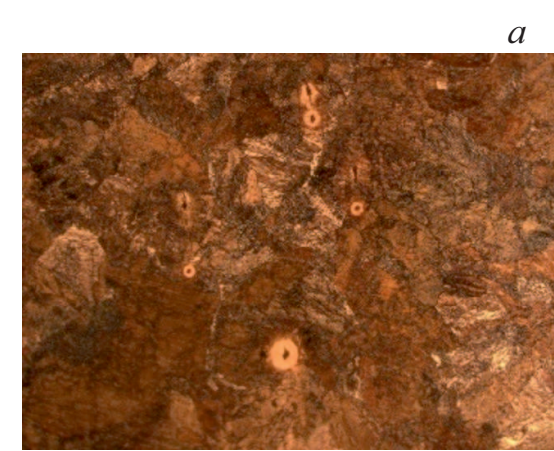

$-10 \mu \mathrm{m}$

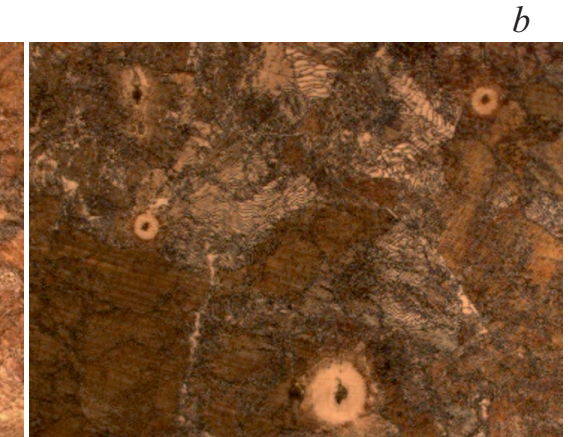

$-5 \mu \mathrm{m}$

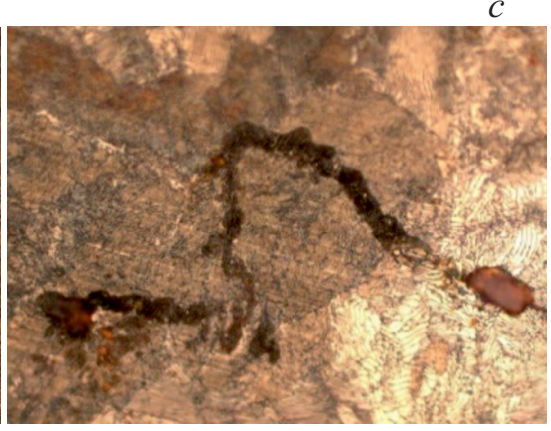

$-5 \mu \mathrm{m}$

Рис. 7. Зарождение микротрещин от строчек вдоль прокатки $-a, b$ и микротрещины у поверхности разрушения $-c, d$.

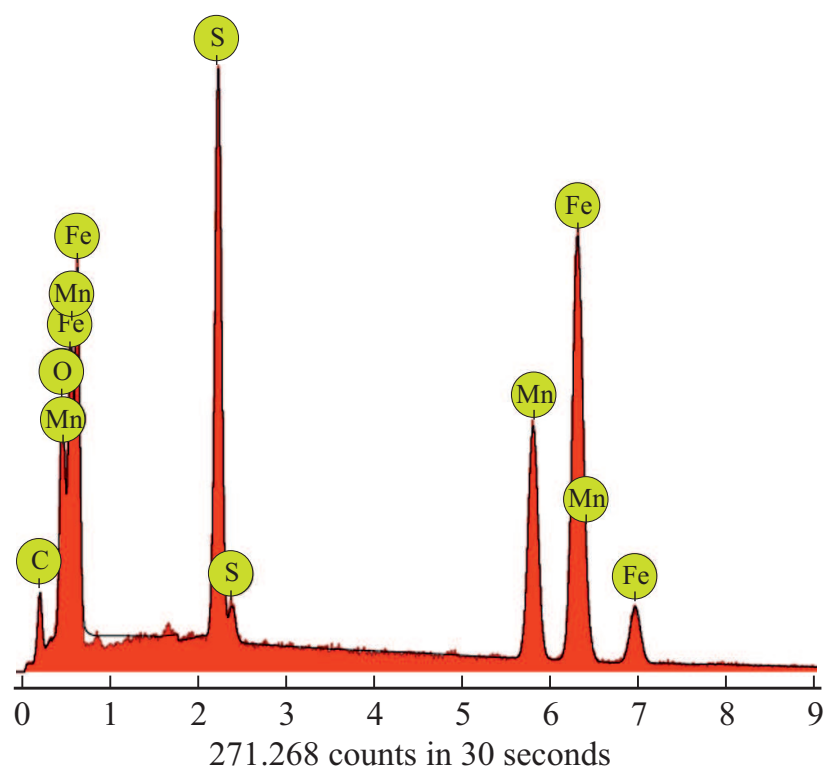

Рис. 8. Спектр элементов внутри трещины (рис. $7, d)$.
Область 2. Промежуточный этап разрушен и я. Началом возникновения дефекта внутренней продольной трещины являются микротрещины от скоплений неметаллических включений, вытянутых при прокатке в виде строчек-дорожек, которые видны на фото микроструктуры (рис. 7, $a, b$ ), а на рис. 7,,$d$ видны микротрещины, расположенные близко к поверхности разрушения.

Подтверждением зарождения трещин на неметаллических включениях является микроанализ, проведенный из области трещины (рис. 7,d) - внутри этой трещины выявлены сера и кислород (рис. 8) кроме остальных элементов, характерных для этой стали.

Область 3. Начальный этап разрушения. Структура начальной области разрушения в центре представляет пластинчатый перлит с довольно мелким зерном, что видно из табл. 3 и на рис. 9, a. Ближе к поверхности разрушения в отдельных местах этой области наблюдаются зародившиеся микротрещины вдоль строчек от прокатки (рис. 9, $b$ ). 


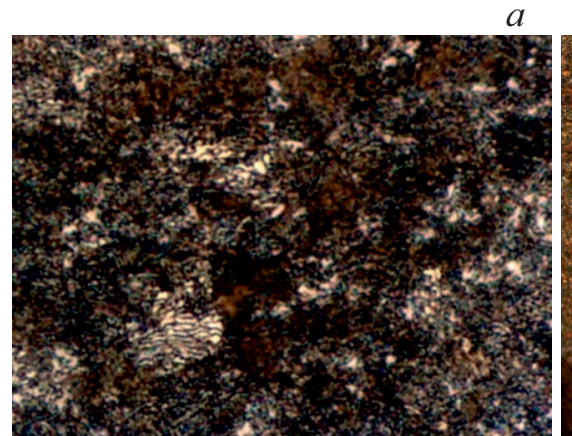

$-2 \mu \mathrm{m}$

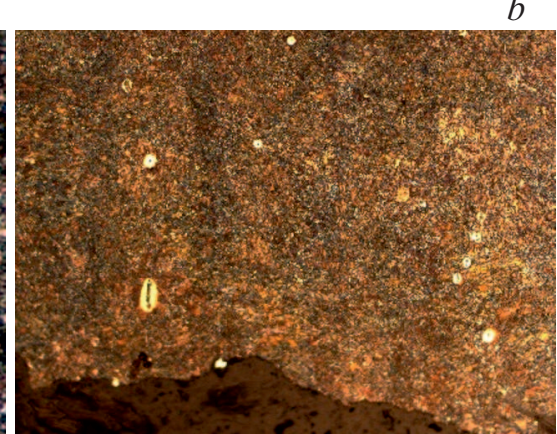

$-20 \mu \mathrm{m}$

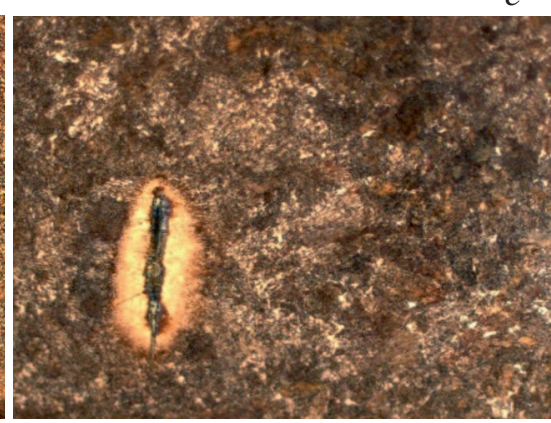

$-5 \mu \mathrm{m}$

Рис. 9. Структура стали в центральной области $-a$; у поверхности разрушения $-b, c$.

\section{4. Выводы}

1. На поверхности разрушения рельса выявлено три области, различающиеся по хрупкости (\% волокна в изломе) - самое хрупкое разрушение наблюдается на по- следнем этапе разрушения рельса, где кроме воздействия нагрузок происходит и нагрев металла.

2. Самая высокая прочность (микротвердость) наблюдается в средней самой протяженной области разрушения, что мало коррелирует с законом Холла-Петча, согласно которому наибольшая прочность должна быть в начальной стадии разрушения, где размер зерна минимальный.

3. На конечном этапе разрушения характер деформации имеет черты волнового течения с сеткой микротрещин с поверхности разрушения. С развитием разрушения размер зерна перлита увеличивается, как и размер ламелей перлита и цементита, а в некоторых местах в результате значительного нагрева и интенсивных пластических деформаций происходит разрушение зерен перлита, цементит растворяется, и образуется аустенит, а в некоторых местах пластинчатый перлит переходит в глобулярный.

4. На заключительном этапе разрушения выявлены области динамической рекристаллизации аналогичные наблюдаемым при ударном нагружении.

5. Микроанализ показал, что зарождение трещин происходит на металлических включениях, богатых серой и кислородом.

\section{Конфликт интересов}

Авторы заявляют, что у них нет конфликта интересов.

\section{Список литературы}

[1] В.М. Тихомиров. Изв. Транссиба 13, 101 (2013).

[2] В.В. Каминский, Н.В. Шаренкова. ФТТ 61, 1287 (2019).

[3] O. Orringer, J.M. Morris. Theor. Appl. Fract. Mechan. 1, 23 (1984).

[4] O. Orringer, J.M. Morris, D.Y. Jeong. Theor. Appl. Fract. Mechan. 5, 63 (1986).
[5] C-S. Kim, K-W. Chung. IJR Int. J. Railway 5, 71 (2012).

[6] H.A. Aglan, M. Fateh. J. Mechan. Mater. Struct. 2, 335 (2007).

[7] S. Atroshenko. AIP Conf. Prceed. 1748, 030005 (2016).

[8] Ю.Ф. Иванов, К.В. Морозов, О.А. Перегудов, В.Е. Громов. Изв. вузов. Черная металлургия 59, 576 (2016).

Редактор Т.Н. Василевская 